\title{
The effectiveness of hydrotherapy in patients with osteoarthritis of the knee
}

\author{
Gonçalves, C. M. 1; Cabral, T. M. 2; Silva, K. M. G. ${ }^{3}$; Nascimento, L. S. G ${ }^{4}$ \\ 123 Estudantes do curso de Fisioterapia-UNIBRA; ${ }^{4}$ Mestre em Fisioterapia pela UFPE e \\ pesquisadora do laboratório LANA.
}

\begin{abstract}
Introduction:Osteoarthritis is a chronic degenerative disease that affects articular cartilage. Its signs and symptoms include morning stiffness, pain, decreased range of motion in the affected joint, limitations in functional activities, deformity with osteophyte formation, swelling and stiffness in the drive. Hydrotherapy is widely used by thrust account, dipping and reduced gravity, which is the differential treatment. Objectives: To analyze through literature reviews and case studies the effectiveness of hydrotherapy in patients with osteoarthritis of the knee. Methods: A literature review was performed from items available in Scielo databases, PubMed, Lilacs, Medline in August 2017, selecting articles published from 2012 to 2017. Results and Discussion: Initially found 55 studies with the proposed theme, among them, 47 were excluded according to the exclusion criteria. Selecting articles 8, 4 case studies and literature reviews 4 . Results report that hydrotherapy helps both assisting in relieving the symptoms and the execution of activities of daily living. Conclusion: Later the acquired data, it can be concluded that the hydrotherapy program on rehabilitation of patients with osteoarthritis patients, was effective in terms of reducing the manifestations of pain and increase in range of motion of the knee. The pool exercises in technique is an excellent environment for rehabilitation of these patients due to buoyant force decrease the force of gravity, therefore, reduces the burden on the injured cartilage when immersed to the chest,Minimizing major changes and making the execution
\end{abstract}

*Correspondence to Author:

Gonçalves, C. M.

Estudantes do curso de Fisioterapia-UNIBRA

How to cite this article:

Gonçalves, C. M.; Cabral, T. M.; Silva, K. M. G.; Nascimento, L. S. G. The effectiveness of hydrotherapy in patients with osteoarthritis of the knee.International Journal of Pain Research and Treatment, 2018, 1:2

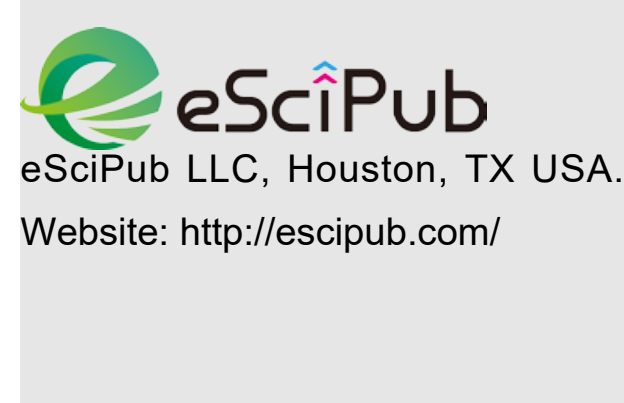

Keywords: Chronic disease; Hydrotherapy; Immersion; Osteoatrosis; Rehabilitation 